\title{
Editor again! Other challenges!
}

\section{Novamente editor! Outros desafios!}

As editor of Revista Dor: Pesquisa Clinica e Terapêutica from 2009 to 2012, with the support of the authors, the editorial board and the boards of the Brazilian Society for the Study of Pain, I had the privilege of having the collaboration of the authors, reviewers and members of the technical staff, index the journal in LILACS, Scielo and Latindex.

As of January 2018, Revista Dor: Pesquisa Clinica e Terapêutica was renamed Brazilian Journal of Pain (BrJP), to provide greater international visibility since scientific journals with English titles are accessed by the entire scientific community, as this is the language used internationally in events and scientific publications.

Now, as the new editor of the BrJP for the 2020-2021 biennium, and feeling the enormous responsibility of the position, I address you, authors and reviewers, to share the objectives to be pursued in this biennium.

The most relevant is to improve the quality, both from an ethical and scientific point of view, of BrJP, a scientific journal aimed mainly at health professionals; researchers, professionals, educators, administrators, and students, interested in the study and treatment of pain.

Another objective is to make the necessary adjustments in the management of BrJP to adapt it to the standards required for indexing on other platforms such as Medline, which is the main database of online bibliographic citations of the NLM Pubmed system, used internationally to provide access to the literature of biomedical journals in the world.

In order to achieve this objective, the policy and scientific quality of the BrJP will be considered, weighing the objectivity, credibility, and quality of the content, through the analysis of the article selection methods, the explicit review process by external peers, adherence to ethical guidelines, disclosure of financial conflicts of interest, correction of errata, explicit retractions, and opportunity for comments and differing opinions to be presented.

To achieve these objectives, the collaboration of the authors is essential by sending original articles, carefully prepared, following the standards of good research practice in humans and animals; preparing review articles carefully following the universal rules for the elaboration of this type of scientific article; and sending well-written clinical cases that make it possible to advance in the study and treatment of pain.

The cooperation of all members of the editorial board is also crucial, carrying through the review of the articles sent, quickly and in-depth, elaborating comments that can improve the content and the form of the text and the author.

The main objective is that each issue of the BrJP is eagerly awaited for being a scientific journal that offers relevant, easy-to-read content that brings new information to those who seek to understand and explain the intriguing mechanisms of pain to improve pain control techniques of their patients, in addition to perfecting and stimulating reasoning and scientific production.

The responsibility that has been entrusted to me is enormous and I am not sparing efforts to live up to the trust of the community that granted me this mission that honors me very much, and you can rest assured that I will do my utmost to take the BrJP to a high scientific level.

In order to face these challenges, I count on your collaboration.

Prof. Dr. Irimar de Paula Posso

Editor for the 2020-2021 biennium

ORCID: (D) http://orcid.org/0000-0003-0337-2531.

(C) Sociedade Brasileira para o Estudo da Dor 